\title{
Equatorial
}

v.8 n.15 | jul/dez 2021

ISSN: $2446-5674$

Dossiê: Educar a quem, educar a quê? Olhares antropológicos sobre a Escola, o Estado e a Nação

\section{Fronteiras e Limites na Prática da Pedagogia da Alternância a Partir do Médio Vale Jequitinhonha-MG}

\author{
Rafael Pereira Santos \\ Mestre em Estudos Rurais - PPGER \\ Universidade Federal dos Vales Jequitinhonha e \\ Mucuri/UFVJM
}

Roberta Alves Silva

Mestra em Estudos Rurais - PPGER Universidade Federal dos Vales Jequitinhonha e

\section{RESUMO}

Este trabalho apresenta sucintamente o surgimento das Escolas Famílias Agrícolas - EFAs e sua expansão da França até o Brasil discutindo as experiências de alternâncias e suas implicações teóricas e práticas. Discutem-se as potencialidades e problemáticas de se manter uma EFA no sentido estrutural e pedagógico no contexto do Vale do Jequitinhonha. A metodologia utilizada embasa-se na análise bibliográfica e pesquisa participante com base em Brandão (1985) a partir das observações na escola e entrevistas junto aos monitores considerando as suas tutorias aos estudantes. Os resultados apresentam a necessidade de engajamento e articulação sociopolítica das EFAs para continuar oferecendo a formação integral dos jovens do campo, que só se realiza a partir da formação continuada dos monitores e efetivo diálogo entre escola, família e comunidade a partir do empoderamento de todos os envolvidos na utilização dos "instrumentos pedagógicos".

Palavras-chave: Alternância; Antropologia da educação; Escola e família; Atividades de retorno. 


\title{
Borders and Limits in the Practice of Alternation Pedagogy from the Middle Vale Jequitinhonha-MG
}

\begin{abstract}
This work briefly presents the emergence of the Agricultural Family Schools (AFS's) and their expansion from France to Brazil, discussing the experiences of alternations and their theoretical and practical implications. The potential and problems of maintaining an AFS in the structural and pedagogical sense in the context of Vale Jequitinhonha are discussed. The methodology used is based on bibliographic analysis and participant research based on Brandão (1985) from observations at school and interviews with monitors considering their tutoring to students. The results show the need for sociopolitical engagement and articulation of the AFS's in order to continue offering comprehensive training to young people in the countryside, which only takes place through the continuous training of monitors and effective dialogue between the school, family and community based on the empowerment of everyone involved in the process use of pedagogical "instruments".
\end{abstract}

Keywords: Alternation; Anthropology of education; School and family; Return activities.

\section{Fronteras y Límites en la Práctica de la Pedagogía de la Alternancia del Valle Medio Jequitinhonha-MG}

\section{RESUMEN}

Este artículo presenta brevemente el surgimiento de las Escuelas Familiares Agrícolas - EFA's y su expansión de Francia a Brasil discutiendo las experiencias de alternancias y sus implicaciones teóricas y prácticas. Se discuten el potencial y los problemas de mantener una EFA's en el sentido estructural y pedagógico no Vale Jequitinhonha. La metodología utilizada se basa en el análisis bibliográfico y la investigación participante basada en Brandão (1985) a partir de observaciones en la escuela y entrevistas con monitores considerando su tutoría a los estudiantes. Los resultados muestran la necesidad de la articulación y el compromiso sociopolítico de las EFA's para seguir ofreciendo una formación integral a los jóvenes del campo, que solo se da a través de la formación continua de monitores y un diálogo efectivo entre escuela, familia y comunidad basado en el empoderamiento de todos los involucrados en el proceso de uso de los "instrumentos" pedagógicos.

Palabras clave: Alternancia; Antropología de la educación; Escuela e familia; Actividades de retorno. 


\section{Introdução}

A recusa de um jovem camponês a ir estudar na cidade, apoiado pelos pais, rompe com o fatalismo até então inquestionado pela naturalidade da existência do saber profundamente ligado à cultura urbana. Esse jovem provocou a atenção de mais jovens da região de Lot-Eat Garron, comunidade de Lousan, na França (GIMONET, 2005). Essas pessoas não sabiam que questionavam o filósofo Sócrates, que dizia que a educação e o saber só poderiam ser construídos na polis (cidade).

O rompimento desse "paradigma" fez emergir um novo fazer pedagógico e, por consequência, uma nova metodologia fortemente arraigada à vida do campo. A alternativa era um sinal de contradição, sobretudo, aos modelos educacionais existentes com características fortemente urbanas, estratificados e alheios à vida do campo.

A partir disso, surgem as bases das Maisons Familiales Rurales - (MFRs) ou (Casas Familiares Rurais) na França, logo após as destruições da primeira Guerra Mundial, oficialmente, no dia 17 de novembro de 1935 (BEGNAMI, SANTOS, FRANCA, 2004). As mesmas adotam como princípio norteador a Pedagogia da Alternância (PA), desde a sua gênese na França, como instrumento pedagógico - tempo de estudo e vivência coletiva na escola e tempo de estudo e moradia com atividades e práticas em casa.

A propagação da versão das MFRs, que aqui no Brasil conhecemos como Escolas Famílias Agrícolas - EFAs, ocorreu pela Europa por intermédio dos ideais do movimento embasado na Secretaria Central de Iniciativas Rurais (SCIR), em 1920, na França. Por meio dos movimentos sociais ligados aos sindicatos e cooperativas foi possível provocar mudanças no campo (BEGNAMI, SANTOS, FRANCA, 2004).

É no interstício da família, "movimento social" e Estado que se pode pensar o sentido de educar colocando a questão da educação diante das identidades emergentes que confrontaram e colocaram a necessidade de se atender a outros sujeitos e pensar outras pedagogias. O modo de educar a partir da Pedagogia da Alternância, por sua vez, se dá e se confronta no bojo destas interações e parcerias junto ao Estado. O Estado de Minas Gerais mantém financeiramente as EFAs, por meio de convênios cuja gestão é dos familiares que garantem a Pedagogia da Alternância por meio do trabalho dos monitores na escola. Surge um tipo de governança entendida enquanto um modo de gerir a educação a partir das necessidades básicas e específicas articulando a educação no tripé: escolafamília e trabalho. 
O Padre Abllé Granereau que incentivou e abriu na sua paróquia a primeira escola em alternância para os jovens preocupava-se com a situação dos sujeitos coletivos do campo numa perspectiva integral, o que não era possível com a escola urbana vigente. As propostas escolares do religioso para as primeiras MFRs não foram fruto de intervenção de intelectuais ou pedagogos, mas, sobretudo, pelo saber-fazer dos próprios agricultores, conforme salientam Gonçalves e Silva (2011). Os pais intuíram que as necessidades formativas deveriam estar em conformidade com as experiências do campo, que deveriam prover a formação para a vida cotidiana.

Os princípios norteadores do currículo propunham a formação com: aprendizagem prática acrescida de observações na comunidade, a partir do livro natural do campo; formação geral para desenvolver a personalidade, por isso, a necessidade de estudar as ciências humanas e matemática; estudo das linguagens para expressar-se oralmente e pela escrita; além disso, a formação e conhecimento sobre a religião enquanto um problema existente para a existência humana, uma vez que, para Abllé "o êxito material, só, não traz felicidade" (NOVE-JOSSERAND apud BEGNAMI, 2005). Portanto, o lugar, os sujeitos e o sentido amplo de educar são as bases da Pedagogia da Alternância.

Para desenvolver esta pesquisa, optou-se pela pesquisa participante, realizada por dois pesquisadores, ambos ex-monitores de EFAs, no Vale do Jequitinhonha. O primeiro foi monitor entre 2012 - 2014 da EFA de Virgem da Lapa e, entre os anos de 2018 -2019, foi monitor da EFA de Veredinha, no Alto Vale do Jequitinhonha. A segunda pesquisadora, por sua vez, foi monitora das EFAs de Jacaré em Itinga e da EFA de Veredinha. Deste modo, o conhecimento prévio e as experiências no modo de olhar, entender, experimentar e indagar, contribuiu para melhor compreender o contexto de pesquisa e aprofundar o diálogo com monitores.

A observação se deu durante 2 semanas, em 2019, na escola. As entrevistas ${ }^{1}$ com os monitores e ex-monitores da EFA de Virgem da Lapa foram realizadas em 2020. Os monitores entrevistados atuaram entre os anos de 2015 e 2020. As entrevistas foram realizadas na cidade de Virgem da Lapa (2 entrevistados) e Araçuaí (3 entrevistados).

O horizonte de entendimento nas entrevistas e observações se deu a partir dos relatos de experiências prévias dos monitores sobre a relação e possíveis rupturas nos tempos e espaços vivenciados na Pedagogia da Alternância, observando as perspectivas dos monitores sobre o Tempo Escola e Tempo Comunidade, suas potencialidades,

\footnotetext{
${ }^{1}$ Os entrevistados gravaram áudio dando o direito à publicidade das entrevistas e de sua identidade. Os áudios serão guardados em arquivo por 5 anos.
} 
desafios e as nuances que emergem na interface escola e família. Portanto, a metodologia desta pesquisa atenta-se ao fulcro central da pedagogia da alternância que é como se concatenam as ações educativas na comunidade e na escola.

A partir disso, este trabalho tem como objetivo discutir as potencialidades e desafios vivenciados pela EFA de Virgem da Lapa no contexto do Vale do Jequitinhonha. A seguir, trazemos no primeiro tópico uma síntese do desenvolvimento das EFAs no Brasil; depois, discutimos algumas considerações sobre o surgimento da Pedagogia da Alternância até o desenvolvimento dela no Brasil e no Vale do Jequitinhonha; por fim, abordamos as relações e fronteiras vivenciadas no tempo escola e tempo comunidade, considerando as potencialidades engendradas pela EFA a partir das entrevistas junto aos monitores e observação da EFA de Virgem da Lapa.

\section{A gênese da alternância no Brasil: uma semente lançada}

Embora as MFRs tenham surgido na França, o modelo existente no Médio Jequitinhonha, conforme Begnami, Santos e Franca (2004), é resultado da importação do modelo de Pedagogia da Alternância trazido pelos italianos para o Brasil a partir de entidades católicas articuladas com o poder político vigente. De modo geral, a alternância se dá no tempo de estudos na escola como internato e tempo em casa para aplicar/ampliar/confrontar os conhecimentos.

A expansão e o resultado positivo possibilitou que as MFRs fossem reconhecidas pela burocracia do Estado francês na década de 1960. Os desdobramentos e a funcionalidade dos métodos aplicados pela Pedagogia da Alternância ganhou confiança e se estabeleceu em outros países: "Itália, Portugal, continente Africano, América do Sul e do Norte, no Caribe, Polinésia, Ásia, América do Norte, Província de Quebec e Canadá" (GONÇALVES; SILVA, 2011, p. 149).

A trajetória das EFAs no Brasil se inicia a partir de 1968 no estado do Espírito Santo pelo Padre Humberto Pietrogrande no bojo das pastorais sociais da Igreja Católica, que obteve apoio do Movimento Educacional e Promocional do Espírito Santo (MEPES). A preocupação inicial era combater a situação de risco em virtude da crise econômica e social dos moradores do sul do Espírito Santo. Essa influência possibilitou a disseminação das EFAs para as demais macrorregiões do Estado brasileiro (GONÇALVES; SILVA, 2011). 
É importante salientar que a primeira experiência de EFA no Brasil foi desvinculada do formalismo do Estado. Entre os espaços de tempo de 1973 e 1987, difunde-se a expansão da metodologia da EFA. A expansão foi mais profícua, sobretudo, nos estados do Nordeste e Norte do Brasil, em seguida chegou a Minas Gerais e posteriormente a outros estados. Após a consolidação de várias EFAs, foi criada a União das Escolas Famílias Agrícolas do Brasil (UNEFAB), em 1982. A criação da UNEFAB teve como objetivo articular e fortalecer a formação por alternância.

O surgimento das EFAs em Minas Gerais-MG tem como característica marcante o papel dos movimentos sociais e das Comunidades Eclesiais de Base (CEBs) da Igreja Católica no fim dos anos 1970 e princípio dos anos 1980 (AMEFA, 2004). A Associação das Escolas Famílias Agrícolas - AMEFA surgiu após a criação de muitas EFAs em MG, entretanto ela articula e assessora as EFAs no sentido pedagógico e para garantir o repasse financeiro do Estado para as EFAs. Foi nesse contexto que emergiram inúmeros Sindicatos de Trabalhadores e o fortalecimento e organização dos homens e mulheres do campo. Há uma relação de autonomia das EFAs em relação à AMEFA.

A primeira EFA implantada em Minas Gerais-MG foi na cidade de Muriaé, na região da Zona da Mata, em 1984. Atualmente em MG, a região que mais tem unidades e adota a metodologia da EFAs é o Médio Vale do Jequitinhonha (GONÇALVES; SILVA, 2011). Isso se deve ao engajamento de lideranças comunitárias, formação no interior das Comunidades Eclesiais de Base (CEBs) e parceria com ONGs vinculadas à Igreja Católica que passaram a estimular o financiamento da estrutura física e pedagógica. Nos Vales do Jequitinhonha como um todo, elas estão presentes nas cidades de: Virgem da Lapa, Itinga, Ponto dos Volantes, Padre Paraíso, Araçuaí, Itaobim, Jequitinhonha, Comercinho, Turmalina (extinta por má gestão) e Veredinha.

As EFAs têm em sua metodologia central a divisão do formativo em: Tempo Comunidade (TC), período em que o estudante aprende em casa, podendo ser 1 semana ou 15 dias na família, aprendendo com os pais e fazendo as atividades escolares; e 1 semana ou 15 dias no Tempo Escola (TE), onde aprendem na teoria e na prática.

Sendo assim, a família e a escola tornam-se lugares de aprendizagem teórica e prática voltada para a agricultura, zootecnia e as disciplinas da Base Comum (biologia, geografia, português, dentre outras) e a gestão da vida no campo. Além disso, esse programa deseja atender às necessidades dos jovens e do seu meio. Isso implica a busca pelo desenvolvimento integral (BEGNAMI, SANTOS, FRANCA, 2004). 
Essa busca é compreendida como a formação intelectual sólida; formação ética pautada no modo de produção agroecológica, o que implica ter uma postura em relação às mazelas do agronegócio; formação espiritual, uma vez que os bens materiais e intelectualismo não são a única fonte de felicidade e uma formação aberta aos movimentos sociais do campo que têm bandeiras do intercâmbio de saberes escola x família, pautas do feminismo e a pauta da reforma agrária.

\section{Problematização das relações e fronteiras entre tempo escola (TE) e tempo comunidade (TC): instrumento de construção do saber a serviço do campo}

É perceptível que há uma literatura aparentemente uniforme em se tratando da proposta da Pedagogia da Alternância (PA) e sobre as Escolas Famílias Agrícolas (EFAs) do Brasil (AMEFA, 2004). A aparência se desfaz a partir das diversas tonalidades de alternâncias que se manifestam na eficiência ou ineficiência nos ambientes em que ela é adotada, mas no todo o que se diferencia é a temporalidade das alternâncias e uma maior ou menor aproximação aos movimentos sociais (SANTOS, 2016).

A PA é utilizada por diversos povos, culturas, movimentos sociais e níveis de educação que compreendem desde as séries finais do ensino fundamental até o ensino superior. Dentre estes, pode-se destacar: Escola Itinerante do Movimento dos Trabalhadores Rurais (MST), cursos de licenciatura ofertados pelo Programa Nacional de Educação do Campo (PROCAMPO), Licenciatura em Educação do Campo (LECAMPO) e Programa de Apoio à Formação Superior em Licenciatura em Educação do Campo (PROCAMPO), dentre outras Universidades Federais, Fundações e Instituições que oferecem este curso.

Nos últimos tempos, o PROCAMPO tornou-se curso regular na Universidade Federal dos Vales Jequitinhonha e Mucuri (UFVJM), com público de estudantes em sua maioria de pessoas do Vale Jequitinhonha. Os profissionais formados estão atuando na educação formal e informal, tanto no urbano quanto no rural (assistência técnica ou direta na produção, formação de liderança, assessoria em sindicatos e movimentos sociais). Santos (2016) afirma que a Pedagogia da Alternância vivenciada pelas EFAs do Médio Jequitinhonha foi ampliada, adaptada, aperfeiçoada e até mesmo burocratizada para atender as necessidades do Básico e Ensino Superior, em virtude das exigências do aparelho público estatal. 
Os princípios básicos da PA trazem no seu bojo histórico algumas diretrizes que fixam em dois eixos básicos: finalidades e meios. A respeito das diretrizes, Gimonet (2005) afirma que os princípios básicos, também conhecidos como pilares, refletem um marco histórico invariável. Os pilares, a partir das finalidades, pretendem oferecer uma formação integral que propicie ao jovem condição para construir o seu projeto de vida pessoal, coletivo e o desenvolvimento sustentável do meio. Os pilares são oportunizados a partir dos meios: que é a PA, entendida como um método pertinente e a associação responsável composta pela família, comunidade e órgãos locais que gerenciam a EFA.

Mas afinal, como as nuances de experiência da PA se manifestam? Quais ou qual o principal gargalo que possibilita compreender ou problematizar a PA nas EFAs? De modo geral, os escritos acerca da PA em autores como Puig Calvò e González García (2018) apresentam pensamentos harmônicos acerca da relação TE e TC. Para eles, o TE e TC apresentam-se como um período formativo que se reparte entre meio socioprofissional, família e a escola. Tudo acontece efetivamente a partir da relação essencial entre escola e o lugar onde mora ou se organiza comunitariamente o estudante.

De acordo com Silva (2005), há vários autores que propõem diversas tipologias a partir de diversos critérios. De maneira geral, as tipologias de alternância se adaptam ao meio e ideologias em que ela é adotada. Para Silva (2005), Girod l'ain foi o pioneiro em estudar a alternância descrevendo a sua relação entre teoria, prática e economia para que os jovens do campo fossem inseridos no mundo do trabalho ou ensino superior.

Para AMEFA (2004), o primeiro a tratar analiticamente sobre a alternância foi Bourgeon, em 1979. Bourgeon (1979) afirma que podem existir 3 tipos de alternâncias subjacentes, sendo elas: falsa alternância, alternância aproximativa e alternância real. A Falsa Alternância é apenas um simulacro da alternância e introduz ao que ela deveria ser - nela se observa a imposição dos estudos sobre as práticas ou vice-versa. Na Alternância Aproximativa, há uma organização didática correta em que se busca associar teoria e prática de forma incipiente, mas não se busca o desenvolvimento das finalidades da PA, que é o envolvimento social, econômico e formativo integral do estudante.

A Alternância Real, por sua vez, possibilita uma junção das atividades no seio da família e escola, relacionando as práticas e refletindo sobre as razões desenvolvidas a partir de suas propostas, de tal modo que o formando construa seu projeto de vida de forma analítica. Portanto, na Alternância Real, a formação integral e o desenvolvimento do meio se dão efetivamente a partir da pedagogia da alternância. 
Os discursos produzidos sobre as relações e possíveis limites das modalidades do TE e TC na Pedagogia da Alternância são pertinentes, uma vez que eles são a essência da PA. O TE e TC já são utilizados desde o ensino fundamental até o ensino superior, inclusive na pós-graduação na Universidade Federal de Minas Gerais - UFMG (Pósgraduação em Educação do Campo) e tantas outras espalhadas pelo Brasil.

No Brasil, o primeiro documento oficial que trata da PA como modalidade de ensino é a LDB 9394/96 (BRASIL, 1996). O Art. 23 afirma que, na organização do Ensino Básico, a educação poderá acontecer em alternância regular e em alternância de períodos de estudos. A decisão oficial aconteceu através do Conselho Nacional de Educação (CNE/CEB/2006 No 1), que declarou que os dias em que o jovem permanecesse em casa são também dias letivos. Certamente, essa foi uma conquista que fortaleceu a PA, para além das fronteiras dela mesma.

Embora o TE e o TC tenham surgido enquanto nomenclatura no PRONERA, já era vivenciado nas EFAs. Indubitavelmente, a vivência do TC e do TE possibilitam reflexões a partir de seus princípios, conceitos, metodologias que devem ser debatidos na comunidade, escola e na academia para melhor se desenvolver e multiplicar em outros níveis da Educação do Campo, por exemplo. Segundo Martins, Rocha e Martins (2012), o TC e TE têm forte presença e articulação com a noção de territorialidade, uma vez que a vida no campo contribui para ampliar o desenvolvimento das habilidades e competências existentes e adormecidas nos sujeitos sociais do campo.

Para o Médio Vale do Jequitinhonha, essa noção é de importância capital. A discussão acerca do território nos lança para reflexões mais profundas do contexto social, político, identitário, sustentável e, por consequência, o engajamento e a intervenção na realidade. Tempo e espaço convergem dinamizando os saberes e fazeres dentro da comunidade. O TC e TE dão condições para formar as identidades e transformar a realidade material por cada jovem, por isso eles tornam-se o chão da existência.

A partir das entrevistas, foi possível entender como a EFA de Virgem da Lapa foi importante para o contexto do Vale e para o fortalecimento da formação em educação do campo. A EFA de Virgem da Lapa se propõe a estar intimamente ligada à realidade cultural, econômica, social e climática do Vale. Sem dúvidas, o Vale Jequitinhonha não se limita à carência econômica. Os problemas de ordem financeira devem-se ao fato de que o Vale ficou desassistido desde a década de 1920 até 1980 pelas políticas públicas. Quando 
elas chegaram, sob a égide desenvolvimentista, trouxeram expropriação de territórios e imposição de monocultivo do eucalipto e café nas terras devolutas ${ }^{2}$.

A cultura manifestada no ser e fazer cotidiano dos homens e mulheres do Vale é, em si, um modo de resistir e reinventar. Santos (2016), ao pensar a educação das EFAs no Médio Jequitinhonha, e Guerreiro (2008), ao estudar os canoeiros do Rio Jequitinhonha, observaram os nichos de resistências na cultura cotidiana como modo de driblar as adversidades do pouco emprego e acesso às terras férteis.

A pedagogia da alternância foi apresentada pelas Comunidades Eclesiais de Base num contexto confuso de discurso de pobreza rural no Vale. Na verdade havia fartura e tempos de crise. Nas crises os políticos aproveitavam para levar vantagem com discurso de miséria. A EFA de Virgem da Lapa possibilitou diminuir o número de analfabetismo no campo, na época era necessário atender esse público. Anos depois, passou a atender somente do $6^{\circ}$ ao $9^{\circ}$, isso porque o município e estado não ofereciam escolas nem transporte da escola para as comunidades. Tem muitos casos em que para o estudante ir e vir para estudar na cidade, ele ficaria mais tempo na estrada do que na escola ou em casa. Nos últimos 10 anos, o êxito da EFA de Virgem da Lapa se tornou um viveiro para pensar outras escolas do $6^{\circ}$ ao $9^{\circ}$ aqui no Vale, e hoje a maioria das escolas atendem somente o Ensino Médio técnico em agropecuária. Um dos principais desafios da EFA hoje é garantir o Bolsa Aluno no Estado e garantir que o Estado repasse o Bolsa Aluno da União. É isso que garante monitor motivado. O monitor mora na EFA e doa sua vida. Acontece de o Estado de MG ficar 5 meses sem repassar a verba. (Antônio Carlos Ferreira, ex-monitor de EFA, entrevista, 10/12/2020 - Araçuaí -MG).

A Pedagogia da Alternância a partir da EFA de Virgem da Lapa disseminou para o Vale a necessidade de se pensar a questão da igualdade-diferença e diversidade-unidade, no sentido que o contexto de inúmeras comunidades do campo precisavam de uma pedagogia que atendesse as crianças por sua diversidade - uma vez que pensar a unidade da educação impõe pensar atender diferenças e, ao atender as diferenças de forma equânime, a educação pode se aproximar da igualdade de conhecimentos a todos.

A partir das análises de Certeau (2012), é possível observar que as estratégias cotidianas de resistência, no nível micropolítico, são realidades que endossam uma ação frente ao cenário hostil, por isso é preciso transgredir as imposições e inventar ou adaptar-

\footnotetext{
${ }^{2}$ Essa temática não será tratada aqui devido a não ser objetivo deste artigo. Para melhor entender este tema, ver a dissertação "Transformações nos ecossistemas da comunidade tradicional de Monte Alegre: estratégias socioambientais de existência, resistência e reinvenção", de Roberta Alves Silva (SILVA, 2020).
} 
se com estratégias culturais para superar as desigualdades e o natural repressivo. Neste sentido, buscar uma escola para atender no cotidiano um "projeto" de campo para o Vale do Jequitinhonha é pensar a cultura enquanto um elemento vivo que impõe mudanças e não se deixa resignar ao fatídico ou ao folclórico em que intelectuais buscam encaixar o fazer cotidiano do povo no campo.

Por assim dizer, ampliar a PA é um modo de pensar o conhecimento repensando a diversidade de saberes trazidos de casa, outras temporalidades e uma escola que, ao se dizer democrática, seja capaz de deliberar a partir do coletivo de pais e estudantes. Disso se depreende que, no contexto do Vale, a PA foi um modo de resistir e recriar o saber instituído e por isso a EFA é um saber instituinte que ainda hoje é sinônimo de pluralidadediversidade e unidade-diferença no Vale do Jequitinhonha.

\begin{abstract}
$\mathrm{Na}$ Pedagogia da Alternância, você trabalha na escola a teoria e em casa você faz a prática de modo agroecológico e ainda consegue trabalhar na propriedade de meus pais e ajudar no desenvolvimento. Sabe por que a pedagogia da alternância na faculdade para mim foi um ponto chave, por exemplo, da minha família sou o único que foi para um Universidade Federal em Diamantina. Você sabe, as coisas lá são caras e não tem como a gente parar de trabalhar e nossos pais nos manter lá, eles vivem da roça e por isso, a pedagogia da alternância favoreceu meus estudos. A metodologia diferente trouxe esse novo saber, eu não preciso sair, eu estudo, melhoro a produção no campo (Luciano Barbosa, ex-monitor da EFA Virgem da Lapa, entrevista, 10/12/2010 - Araçuaí -MG).
\end{abstract}

As EFAs, como se pode observar na fala do egresso de EFA Luciano, que é exaluno da Licenciatura em Educação do Campo - UFVJM e ex-monitor da EFA de Virgem da Lapa, possibilitou a continuidade dos estudos e ao mesmo tempo romper com a "importação" de professores das cidades para o campo. É sabido que o referencial de professores urbanos nem sempre considera as especificidades do estudante do campo. Há duas constatações na fala do ex-monitor: a primeira está no fortalecimento do modo de produzir com a qualidade e de maneira agroecológica, a produção a partir do conhecimento do que já se faz e intercâmbios. Em um segundo nível, é possível observar que os próprios sujeitos do campo estão se educando, acessando o nível superior, na pósgraduação e se formando em alternância.

O TC e o TE não podem ser dicotomizados, embora possam acontecer em lugares separados, não podem ser distintos (MARTINS; ROCHA E MARTINS, 2012). Essa situação pode ser constatada nos projetos pedagógicos propostos pela educação do campo 
que partem do princípio de que a vivência na comunidade, no trabalho, na rua e no movimento social são compreendidos como espaços educativos. Nessa perspectiva, não se cogita complementaridade, mas interação no processo de alternância.

O jovem formado no campo tem seu próprio lugar como desafio e possibilidades. As experiências de PA são possíveis desde a formação básica até o nível superior. Ademais, o fortalecimento da educação em alternância implica fortalecer movimentos e coletividades do campo, desde uma melhor formação para acessar políticas públicas e produzir sem agrotóxicos, a partir de insumos do lugar e, por consequência, colocando alimento com melhor qualidade no mercado e na comunidade e pautando uma educação do campo que emancipa seus sujeitos.

\begin{abstract}
Lembro que quando iniciei meus estudos no $6^{\circ}$ ao $9^{\circ}$ - na EFA de Virgem da Lapa pediram para descrever a Pedagogia da Alternância. A PA é um intercâmbio de ideias e conhecimentos entre escola e comunidade. A PA precisa ser criteriosa nesse sentido. Ela é um caminho de valorização do conhecimento científico e popular, seja na forma de cultivar, seja na forma de administrar a terra e até mesmo desenvolver a sua visão de mundo. Essa pedagogia é uma forma de duas visões de mundo se unirem, como uma rede de pesca, na qual todos os fios se completam. (Regiane Souto Souza, monitora da EFA Virgem da Lapa, entrevista, 10/12/2029 - V. da Lapa -MG ).
\end{abstract}

Pensar a EFA é colocar em questão Tempo Escola e Tempo Comunidade, isto é, um jeito de fazer acontecer a educação em espaço e tempo diferenciados. É também considerar e confrontar conhecimentos e saberes gerando intercâmbio de conhecimentos. A PA não tem fim em si mesma, mas é um modo de dizer que a educação deve se adaptar ao contexto, socializar saberes e deixar a escola ser inquirida sobre seus pressupostos pelo fazer-saber cotidiano produzido nas comunidades.

\title{
A vivência "por- e- em" alternância na EFA de Virgem da Lapa no Médio Vale do Jequitinhonha
}

O Vale do Jequitinhonha situa-se no nordeste mineiro. Ele ocupa cerca de 14\% do território mineiro, totalizando cerca de $85.000 \mathrm{~km}^{2}$ (GUERRERO, 2008). Ele tem sua história intimamente ligada ao processo de povoamento de Minas Gerais. A sua povoação inicial efetivou-se através do ciclo do ouro. De acordo com Guerrero (2008), no fim do 
século XVI, o rio Jequitinhonha já havia sido descoberto pelas suas pedras preciosas e metais. Muitos forasteiros vinham em busca do "sol da terra", isto é, o ouro.

O Rio Jequitinhonha nasce em Serro, na serra do Espinhaço. O rio corta o sertão mineiro percorrendo cerca de $1086 \mathrm{~km}$, sendo 888 em terras de Minas e 198 em terras da Bahia. O rio é motivo de orgulho pelos seus moradores, sobretudo, em terras semiáridas. Por muito tempo, foi o principal elo entre Bahia e Rio de Janeiro nas relações comerciais. De acordo com Guerrero (2008) há muitos períodos de silêncio acerca do Vale. Essa constatação implica na dificuldade de se compor sua análise.

Um fenômeno bastante valorizado pelos moradores do Vale são as manifestações culturais que oportunizam uma forma de sociabilidade e interação com a natureza e a linguagem religiosa: Folia de Reis, Vilão, Nove (versos improvisados e cantados com filas - na Festa do Divino Espírito Santo), batuques na Festa de Nossa Senhora do Rosário e o lundu (dança de roda com sucessões de toques nos ombros). No improviso, nessas festas ligadas ao catolicismo rústico ou em danças de origem africana, eles tematizam problemas do cotidiano (diminuição da população rural, trabalho pesado, salário pequeno, falta de água, a morte, provocações e assuntos lúdicos).

Guerreiro (2008) convida a analisar o Vale sob o ponto de vista da intensidade que traz consigo a noção de iniciativa, lúdico e autonomia. O olhar sob o ponto de vista da intensidade permite ultrapassar os limites dicotômicos de pobreza-riqueza, culturamiséria, fartura-carência. A partir das narrativas dos canoeiros que afirmam: "canoa não é força, é opinião" busca entender o viver a vida no Vale. Para o povo dessa região, OPINIÃO remete a uma experiência existencial para além da ideia, trazendo assim uma noção de valor, honra, orgulho e coragem (GUERRERO, 2008).

De certo modo, a economia do Vale é, na sua maioria, oriunda do campo. A agricultura de existência ${ }^{3}$, bem como a criação de pequenos animais dos camponeses e

\footnotetext{
${ }^{3}$ Os densos e amplos estudos do sociólogo José Souza Martins (1985), em seu livro: A militarização da questão agrária no Brasil, aponta que a agricultura de subsistência refere-se a relações não capitalistas dos camponeses. Para ele, o capitalismo atual se produz nas condições sociais e econômicas em que o povo se encontra, mas não se fecha a outras mediações. Em tese, não há agricultura de subsistência, uma vez que não temos uma agricultura pré-capitalista no Brasil. Essa afirmativa deixa a possibilidade de outros modos de reprodução da vida e da existência. As pesquisas de Santos (2018) junto aos pescadores e quilombolas em 10 comunidades ao longo de 5 anos (acrescido de mais 2 de mestrado) concluíram que no Norte de Minas não existe aceitação de um tipo de agricultura de subsistência nos grupos e viu que ali havia um tipo de produção de existência que não era nem tipicamente capitalista e nem de subsistência. As pesquisas de Silva (2020) com quilombolas do Vale do Jequitinhonha também constatou um outro tipo de produção que ela nomeia de existência e reinvenção, ainda que seja fortemente impactada pelo capital.
} 
comunidades tradicionais são bastante recorrentes. As problemáticas não estão nas oscilações climáticas com baixa pluviometricidade, mas na ausência ou na pouca ação das iniciativas governamentais. O monocultivo do eucalipto tem sido um dos principais vilões sobre as comunidades, uma vez que privatizou as terras livres e expropriou os camponeses e povos tradicionais, incentivado pelo Estado nas décadas de 1970 e 1980 (SANTOS, 2016). De modo geral, a economia é assim caracterizada: Alto Jequitinhonha, atividade mineradora; Baixo Jequitinhonha, agropecuária; e no Médio Jequitinhonha, zona de transição. Certo é que a atividade mineradora está em forte decadência.

Segundo Guerrero (2008), a CODEVALE (Comissão de Desenvolvimento do Vale Jequitinhonha) foi criada em 6 de junho de 1966 pelo decreto $n^{\circ} 9.841$. As experiências da CODEVALE foram desastrosas. Seus projetos eram inviáveis, os planejamentos ineficientes e os resultados quando vieram para o Vale foi o monocultivo do eucalipto e a expulsão do homem do campo para as cidades.

O Vale Jequitinhonha possui uma população muito mais rural do que se pensa. Esses dados são mais expressivos no Médio Jequitinhonha. Por outro lado, no campo, faltam homens e mulheres em idade ativa, além disso, a fecundidade está em queda. No total, o Vale Jequitinhonha possui cerca de dois terços de sua população no campo, conforme relatório do Instituto Brasileiro de Geografia e Estatísticas - (IBGE), reafirmado nas análises de Matos e Garcia (2010).

Ainda hoje têm pessoas do campo que buscam os grandes centros: na construção civil, em Belo Horizonte e nas migrações sazonais. Na década de 1980, o caminho mais procurado foi a região canavieira, no interior de São Paulo (SANTOS, 2016). A modernização da agricultura e a migração com sucesso fácil deixou de ser um projeto do jovem do Vale do Jequitinhonha. O sonho de migrar para casar, ajudar a família e comprar carro e moto tem diminuído. De modo geral, os jovens do campo têm investido em atividades no interior da propriedade familiar no vale e/ou oferecendo serviços para o campo conforme salienta Santos (2016), em suas análises.

A EFA de Virgem da Lapa se encontra na Comunidade Cardoso nas margens do Rio Araçuaí, principal afluente do rio Jequitinhonha, no Médio Vale do Jequitinhonha. As familias, na sua maioria, são de origem de lavradores tradicionais e remanescentes de quilombos. Atualmente a escola atende o público do $6^{\circ}$ ao $9^{\circ}$ ano, embora inicialmente a necessidade fosse formar jovens e adultos, em Alternância. Diga-se de passagem, a cidade de Virgem da Lapa e a comunidade eram sede de uma Sesmaria que possuía um expressivo número de pessoas escravizadas, o que se percebe no número expressivo de quilombos 
na cidade (SANTOS, 2016). Atualmente, as turmas de $6^{\circ}$ ao $9^{\circ}$ têm uma média de 20 estudantes. Os estudantes são filhos de lavradores tradicionais, quilombolas, indígenas da Aldeia Pankararu Pataxó e estudantes que moram na cidade, mas têm vínculos com o campo. Ao concluírem o $9^{\circ}$ ano, normalmente, os estudantes vão fazer o ensino médio técnico na EFA de Araçuaí-MG. Em boa medida, a permanência na região para os jovens do campo está relacionada à educação por e em alternância. É por isso que a PA e as relações entre trabalho-educação precisam ser discutidas por sua diversidade e, sobretudo, pela complexidade e seu diferencial.

A realidade específica das EFAs, por sua vez, possibilita problematizar e propor uma educação de qualidade frente aos desafios de diálogo que o modelo educacional vigente do poder público municipal tem ao lidar com os povos do campo.

Como um todo, sabe-se que a educação pública seja ela rural ou na cidade quer sobreviver com recursos mínimos e com o máximo de estudantes em sala de aula, o que inviabiliza pensar uma qualidade básica geral na educação básica ofertada pelos estados e municípios, além de ser um modelo de ensino padronizado que muitos educadores têm dificuldades de alterar. Ademais, os Projetos Políticos Pedagógicos (PPP) de várias escolas do campo sob a regência do poder público municipal apresentam uma uniformidade que acaba por usurpar a diferença entre as peculiaridades inerentes às identidades deste povo que vive no campo.

Os agricultores e agricultoras dos Sindicatos de Trabalhadores, Prefeitura Municipal com caráter popular e Caritas Diocesana de Araçuaí possibilitaram nascer o esboço das primeiras EFAs no Vale, sendo a EFA de Virgem da Lapa a primeira. A implantação das EFAs no Vale é provida de um território rico por vários aspectos, dentre eles: a formação política de classe por melhor qualidade de vida. Os Sindicatos, Pastorais Sociais, ONGs e Universidades Federais já possuem técnicos formados pelas EFAs (GONÇALVES E SILVA, 2011). Essa gama de instituições e a busca por parcerias e técnicas adaptadas à realidade tem possibilitado produzir e conhecer mais.

Esses sujeitos sociais organizados são desafiados para intervir na realidade do Vale frente às migrações para usinas de produção de álcool de cana de açúcar no interior de São Paulo, colheita do café no sul de Minas e na comercialização ambulante nas praias do litoral norte de São Paulo, dentre outras experiências de trabalhos sazonais em outras regiões do estado e do país com inúmeros jovens analfabetos no campo.

A observação dos agricultores tradicionais constatou a necessidade de implantação de uma EFA no campo para combater a migração e, por consequência, envolver as 
comunidades (AMEFA, 2004). Os agricultores foram atraídos com os objetivos primordiais de buscar reduzir as fronteiras na relação escola-família e vida no campo. Deste modo, a EFA apresenta-se como uma proposta alternativa em relação às demais escolas existentes atualmente no campo que oferecem uma educação engessada no pedagógico, no cronológico e no "urbanocentrismo".

A EFA oferta as séries finais do ensino fundamental. Antes, ela disponibilizava o ensino baseado na Educação de Jovens e Adultos EJA, todavia, foi diminuindo o número de estudantes com idade a partir dos 14 anos, para cursar as séries finais do ensino fundamental. A partir daí, em 2008, tornou-se oficialmente regular recebendo estudantes a partir de 11 anos de idade (Marinete Dourado, ex-monitora da EFA Virgem da Lapa, entrevista, 20/05/2019 - Araçuaí -MG).

A PA, enquanto modalidade de ensino oferecida nas EFAs, corresponde a um campo de possibilidades e meios que vinculam a valorização dos saberes e fazeres das famílias e comunidades dos estudantes. Isso é visto como potencial para engendrar transformações agroecológicas pautadas no produzir com qualidade, formar intelectualmente e se imbuir dos movimentos sociais pensando a partilha da terra.

A EFA de Virgem da Lapa lança uma necessidade lógica de reflexão das instituições instituídas, a exemplo das escolas rurais com lógica urbana para defender uma escola instituinte, que seja nascida dos anseios e gerida pelos seus interessados, no caso os pais. A escola instituída é essa que oferece uma educação a partir dos anseios dos pais e dos jovens. Isso se dá por meio de uma associação, legitimamente instituída e atuante nas decisões das EFAs. A título de exemplo, os pais que são associados contratam os monitores de seus filhos.

$\mathrm{Na}$ EFA, busca-se transgredir as disciplinas amorfas aguçadas pelo material didático com forte caráter "urbanocêntrico". Os planos de ensino das EFAs possibilitam a análise de temáticas próprias do campo: zootecnia, agropecuária, administração da propriedade, permacultura, espiritualidade e formação personalizada.

Outro fato corrente são os diálogos através dos ROTEIROS DE PESQUISA que visam construir o saber além das fronteiras canônicas do currículo. Afinal, o saber se produz de dentro da comunidade para o interior das EFAs e vice e versa. O saber vindo de casa, por meio dos roteiros construídos e sistematizados na EFA, é passível de intervenção ou análise de acordo com o resultado da pesquisa. É nesse sentido que a discussão do currículo da EFA possibilita uma transgressão política, ética, pedagógica. 
Há uma diferença substancial entre educação do campo e educação rural. A educação rural é um projeto que suplanta as diversidades e apenas impõe lógicas urbanas em escolas nomeadas rurais. Teóricos como Arroyo Caldart e Molina (2008) defendem que é necessário romper com a ideia de educação rural. A Educação no campo implica dizer que este espaço possui uma carga e uma historicidade educativa numa perspectiva de territorialidade, isto é, faz parte da identidade e/ou identificação ao campo.

A educação do campo implica romper com o currículo urbanocêntrico e a suplantação do campo. Na prática, o urbanocentrismo na educação implica sair do campo de madrugada todos os dias para a cidade, ser vítima de preconceitos e racismos em sala de aula, ter professores que pouco consideram as peculiaridades do campo. Isso se estende para a negação ou silenciamento da diferença da temporalidade da colheita, das cheias dos rios, ausência de acesso de carro em suas casas e formação do campo precária ou inexistente aos profissionais que atuam com os educandos do campo. A educação do e no campo não surge somente para tornar tênue o termo educação rural, mas para estabelecer um diálogo seguido de uma proposta filosófica e pedagógica diferenciada que busque facilitar o protagonismo do jovem.

De acordo com Silva e Gonçalves (2011), as EFAs do Vale existem imersas em precariedade de financiamento da proposta de formação de monitores e manutenção da estrutura. Tais deficiências tornadas visíveis não propiciam um atendimento satisfatório aos anseios. Essa situação compromete a elevação da qualidade e desenvolvimento dos princípios basilares da PA através da sua proposta pedagógica e metodológica.

Para que haja uma relação efetiva entre escola e comunidade são essenciais as tutorias como espaço de diálogo específico com as famílias. A escola precisa ir à casa do estudante para observar transformações ou permanências após este ingressar no ambiente escolar. Ao fim da semana, os pais assinam as atividades realizadas em casa e os tutores assinam as atividades realizadas na escola. $\mathrm{O}$ acompanhamento tutorial é realizado na escola por meio da análise do Caderno de Alternância, onde está o registro do Tempo Escola e do Tempo Comunidade. As orientações acontecem uma vez por semana para analisar como foram feitas as atividades de estudos e trabalho na escola e em casa. Portanto, a escola e família acompanham o estudante no mesmo instrumento.

Em se tratando da formação dos monitores da EFA de Virgem da Lapa, segundo Santos (2016), mais de dois terços já possuíam cursos superiores. O corpo de monitores, com formação superior, apresenta uma vazão muito expressiva, e isso implica perder quem tem domínio da proposta pedagógica diferenciada. Além disso, torna-se difícil de compor 
o corpo docente nas evasões se considerada a exigência desta modalidade de pedagogia da alternância (morar na alternância na escola, dedicação exclusiva, múltiplas atribuições, certa moral preconceituosa e a instabilidade salarial e empregatícia que anualmente precisa ser dialogada com o ente governo do Estado e União).

Segundo Gonçalves e Silva (2011), a secretaria executiva da AMEFA afirma que a condição salarial implica na evasão de monitores treinados. Ele complementa que só o querer da comunidade não é suficiente, mas é necessário, antes de tudo, o financiamento da proposta pelas ações governamentais, caso contrário a precariedade impossibilita as condições de aplicação da PA.

O Tempo Escola e Tempo Comunidade são duas unidades indissociáveis. Analisar essas e reformular o TC e TE de acordo com a realidade é necessário para se garantir ensino-aprendizagem. Com isso, quer se chegar à unidade da temporalidade e atender às diferenças por meio da socialização dos saberes, fazeres e recriação do instituído nas resistências cotidianas, por causa da liberdade e autonomia dos povos da terra, das águas e das florestas.

\section{Considerações Finais}

O Vale Jequitinhonha está além dos contrastes de pobreza material e riqueza cultural. A agricultura camponesa e tradicional constitui a força motriz da economia do Médio Jequitinhonha, embora não apresente dados expressivos, nutre a vida em todas as suas formas. A Pedagogia da Alternância é um meio para se chegar às finalidades ideais que é buscar um envolvimento solidário, anticapitalista, antirracista e agroecológico dentro de uma perspectiva ética integrada às especificidades dos sujeitos do campo.

A Pedagogia da Alternância torna-se essencial, não somente para dar condições de escolhas de permanecer ou sair do campo, mas, sobretudo, para valorar a vida em sua dinamicidade. A proposta de formação integrada: educação, trabalho, formação pessoal, comunitária, espiritual, ética, estética e sustentável são ofertados pelas EFAs, em meio à precariedade de financiamento.

Por outro lado, não se pode negar que a qualidade pode ser limitada pela carência de capital humano e financeiro. A EFA de Virgem da Lapa é uma proposta lançada no devir da história. No Médio Vale do Jequitinhonha, as EFAs estão em um solo fértil e dinâmico de movimentos sociais, populações tradicionais, ONGs, movimentos eclesiais e 
Universidades que são instituições parceiras no processo de construção de possibilidades nas fronteiras e limites em busca do Bem Viver no campo.

\section{Referências}

AMEFA. Escola Família Agrícola: construindo educação e cidadania no campo. Belo Horizonte: O Lutador, 2004.

ARROYO, Miguel G; CALDART, Roseli S.; MOLINA, Mônica C. (Org.). Por uma educação do campo. 3. ed. Petrópolis, RJ: Vozes, 2008.

BARBOSA, Luciano. Entrevista concedida a Rafael Pereira Santos. Virgem da Lapa, 20 de dezembro de 2019.

BEGNAMI, João B. Pedagogia da Alternância como sistema educativo. Revista da Formação por Alternância, v.1, n.2, (2005-). União Nacional das Escolas Famílias Agrícolas do Brasil (UNEFAB). Belo Horizonte: Lutador, 2005.

BRANDÃO, Carlos R. (Org.). Repensando a Pesquisa Participante. São Paulo: Brasiliense, 1985.

BRASIL, Lei de Diretrizes e Bases. Brasília-DF, 1996.

BRASIL. CNE/CEB; $n^{\circ}$ 1/1997, aprovado em 26 de fevereiro de 1997. Disponível em:

http://portal.mec.gov.br/index.php?option $=$ com content\&view $=$ article\&id $=12992$.

Acesso em 20 de fev. de 2015.

CERTEAU. Michel. A Cultura no Plural. 7. ed. Rio de Janeiro: Papirus - Coleção Travessia, 2012.

FRANCA; Marinalva J; BEGNAMI, João B; SANTOS, Idalino F. (org). Escola Familia Agricola: construindo educação e cidadania no campo. Belo Horizonte: O Lutador, 2004.

FUNDO CRISTÃO PARA CRIANÇAS. Escola Família Agrícola: um novo caminho para o Vale Jequitinhonha. Belo Horizonte, 1996.

GIMONET, Jean C. Alternância, Adolescência e pré-adolescência. Revista da Formação por Alternância, União Nacional das Escolas Famílias Agrícolas do Brasil (UNEFAB),v.1, n.1. Belo Horizonte: Lutador, 2005.

GONÇALVES, Mônica A.; SILVA, Mara. A. Princípios norteadores das EFAs: potencialidades e desafios para o funcionamento no Vale do Jequitinhonha. In: SOUZA, João V. A.; NOGUEIRA, Maria D. P. (Org.) Vale do Jequitinhonba: desenvolvimento e sustentabilidade. Belo Horizonte: UFMG/PROEX, 2011.

GUERRERO, Patrícia. O Vale Jequitinhonba e seus Contrastes. Tese de (Doutorado em educação). Universidade Federal de Santa Catarina, Florianópolis, 2008. 
LOPES, Maria P. Entrevista concedida a Rafael Pereira Santos. Virgem da Lapa, 20 de dezembro de 2019.

MARTINS, José Souza. A militarização da questão agrária no Brasil. Petrópolis: Vozes, 1985.

MARTINS, Maria de F. A; ROCHA, Maria I. ; MARTINS. Territórios Educativos na Educação do Campo, Escola, Comunidade e Movimentos Sociais. São Paulo: Autêntica, 2012.

MATOS, Ralfo; GARCIA, Ricardo. Vale do Jequitinhonba: Formação bistórica, populações e movimentos. In: SOUZA, João V. A. de S, Márcio Simeone Henriques (org.). Belo Horizonte: UFMG/ PROEX, 2010.

NASCIMENTO, Elaine C. do. Revista Contemporâneos: Revista de artes e humanidades Vale Jequitinhonha: Entre a carência social e a riqueza cultural, n.4, maioout., 2009.

PUIG-CALVÒ, P., \& GONZÁLEZ-GARCÍA, J. (2018). La formación por alternancia-dual. Interacciones empresa y centro de formación: acompañamiento y experiência. In: $3 \mathrm{r}$ Congrés d'Economia i Empresa de Catalunya. Recuperado de: https://www.scipedia.com/public/PERE_GARCIA 2018a.

SANTOS, Marinete D. Entrevista concedida a Rafael Pereira Santos. Virgem da Lapa, 20 de dezembro de 2019.

SANTOS, Rafael P. A questão da memória no processo de ensino e aprendizagem da língua patxôhã. Saarbrücken -Alemanha: Editora Novas Edições Acadêmicas, 2016.

SANTOS, Rafael P. Da Existência Ilhada ao Território: estratégias e trajetórias da Comunidade de Croatá, MG na busca de conquistar seu território. [Dissertação de Mestrado]. Diamantina: UFVJM, 2018. 233 p

SILVA, Lourdes H. As Experiências de Formação de Jovens do Campo: Alternância on Alternâncias? Viçosa: Editora UFV, 2003.

SILVA, Lourdes H. Revista da Formação por Alternância, v.1, n.2, (2005-). União Nacional das Escolas Famílias Agrícolas do Brasil (UNEFAB). Modalidades, representações e práticas de alternância na formação de jovens agricultores. Belo Horizonte: Lutador, 2005.

SILVA, Roberta A. Transformações nos ecossistemas da comunidade tradicional de Monte Alegre: estratégias socioambientais de existência, resistência e reinvenção. [Dissertação de Mestrado]. Diamantina: UFVJM, 2020. 144 p. 